\title{
Peertechz
}

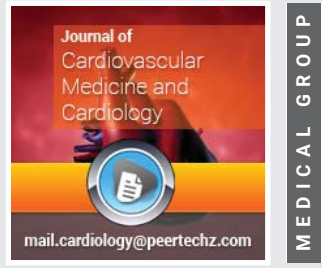

\section{Novel use of contegra valved conduits in idiopathic bilateral brachiocephalic vein stenosis}

\author{
Suraj Wasudeo Nagre ${ }^{1 *}$ and Krishnarao Narayanrao \\ Bhosle $^{2}$
}

${ }^{1}$ Associate Professor, Department of CVTS, Grant Medical College, Mumbai, India

${ }^{2}$ Ex Professor and Head of CVTS, Grant Medical College, Mumbai, India
Received: 05 March, 2021

Accepted: 05 April, 2021

Published: 06 April, 2021

*Corresponding author: Dr. Suraj Wasudeo Nagre, Associate Professor, Department of CVTS, Grant Medical College, 31, Trimurti Building, JJ Hospital Compound, Byculla, Mumbai, 400008, India, Tel: 09967795303; E-mail: surajnagre@yahoo.com

Keywords: Innominate vein thrombosis; Endovascular interventions; Contegra graft

https://www.peertechzpublications.com

\section{Check for updates}

\section{Abstract}

Thromboses of the upper limp and neck veins are rare in comparison with those of the lower extremities. Innominate Vein Thrombosis (IVT) is an elusive vascular disease that is rarely seen, with potentially lethal complications such as sepsis and pulmonary embolism. It is usually secondary to intravenous drug abuse, prolonged central venous catheterization or deep head-neck infections or trauma. The history and examination in patients with an IVT may be vague and misleading. Patients may present with a painful swelling of the neck but they may also be absolutely asymptomatic.

Initial medical treatment of the patients includes thrombolytic, anticoagulant and steroid drug therapies. If the patient's symptoms do not improve with medication, surgical or endovascular interventions are performed. The indications for open, surgical revascularization are rare and usually reserved for patients whose symptoms are refractory to anticoagulation and endovascular treatment.

We report successful decompression of severe venous hypertension of head, neck, face and bilateral upper limb of a 39 year old male patient having symptoms such as facial, neck and bilateral shoulder intermittent edema, occasional dyspnea, chest pain, and headache since 1 year. CT Venography s/o bilateral brachiocephalic vein [Innominate vein] and left subclavin vein stenosis. After all investigations for searching cause of thrombosis all reports normal, nothing found so we called it as idiopathic. We used two contegra valved bovine conduits. Proximal end of the first contegra valve conduit was anastamosed to right distal IJV and distal end to the SVC. The another contegra graft's proximal end was anastamosed to the left distal IJV and distal end to the first contegra graft distal to its valve. It provided promt and effective venous outflow, with complete resolution of the venous engorgement over the face and upper limb, and also a patent graft six months postoperatively.

\section{Introduction}

Thrombosis of the upper limb and neck are rare in comparison with those of the lower extremities. Innominate and Internal Jugular Vein Thrombosis (IJVT) is an exclusive vascular disease that is rarely seen, with potentially lethal complications such as sepsis and pulmonary embolism. Hereditary and acquired conditions predispose to thrombotic phenomena [1]. IJVT is rarely spontaneous, which means there is no apparent predisposing factor for thrombosis (Unsal, et al. 2003) [2]. We report a case of successful decompression of severe venous hypertension of head, neck, face and bilateral upper limb of a 39 year old male patient treated by IJV-SVC bypass using two contegra valved conduit.

\section{Case report}

A 39 year-old male patient has a history of facial flushing and puffiness in the supine position and also while bending down. He also gives history of engorgement of veins over neck and left upper limb in head down position which get resolved when head is up. Colour doppler study revealed obstruction in bilateral innominate and left subclavin veins with dilated superficial veins of neck and upper limb. CT Venography showed bilateral brachiocephalic vein [Innominate vein] and left subclavin vein stenosis with resultant dilatation of bilateral superior intercostal vein and multiple diated superficial venous channels of left upper limb (Figure 1).

After all investigations for searching cause of thrombosis all reports normal, nothing found so we called it as idiopathic. Patient symptoms not relieved by medicines and intervention radiologist was not able to pass guidewire across the stenosis. Hence the decision of open surgical venous bypass was taken.

Patient was operated via a midline sternotomy, with the 
incision extending upwards till lower part of thyroid cartilage. Adequate exposure of the SVC and bilateral internal jugular veins was meticulously performed (Figure $2 \mathrm{~A}$ ).

The thrombosed veins were carefully palpated and the extent of bypass decided. After $100 \mathrm{IU} / \mathrm{kg}$ heparinisation two contegra bovine valved conduits; $12 \mathrm{~mm} \mathrm{X} 10 \mathrm{~cm}$ were used. Proximal end of the first contegra valve conduit was anastamosed to right distal IJV and distal end to the SVC. The another contegra graft's proximal end was anastamosed to the left distal IJV and distal end to the first contegra graft distal to its valve in end to side fashion (Figure $2 \mathrm{~B}$ ). Adequacy of flow was confirmed after releasing the clamps.
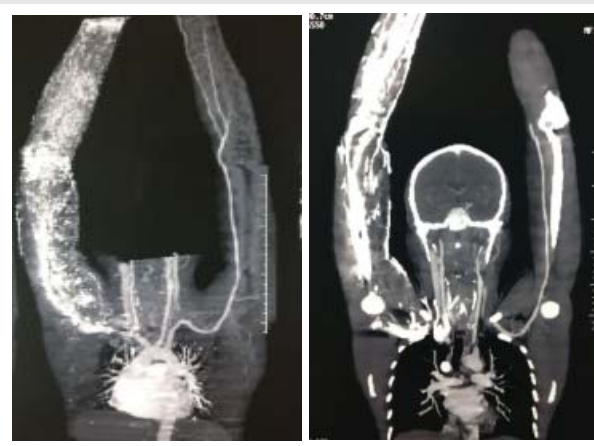

Figure 1: CT Venography showed bilateral brachiocephalic vein [Innominate vein] and left subclavin vein stenosis with resultant dilatation of bilateral superior intercostal vein and multiple diated superficial venous channels of left upper limb.

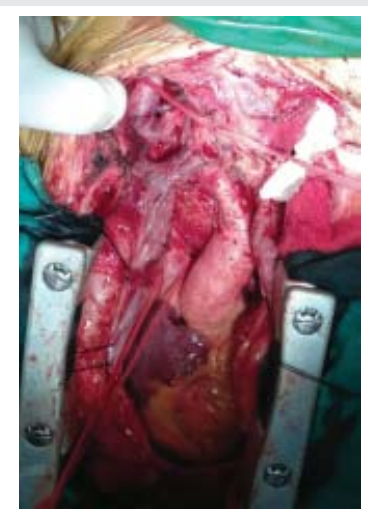

Figure 2A: Adequately exposed SVC and bilateral internal jugular veins.

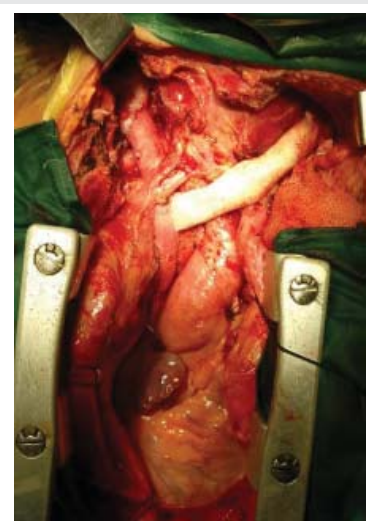

Figure 2B: Proximal end of the first contegra valve conduit was anastamosed to right distal IJV and distal end to the SVC. The another contegra graft's proximal end was anastamosed to the left distal IJV and distal end to the first contegra graft distal to its valve in end to side fashion.
Patient was started post operatively on inj heparin $5000 \mathrm{IU}$ six hourly and tab warfarin $5 \mathrm{mg}$ once daily at $6 \mathrm{pm}$. Heparin was discontinued once the INR reached between 2 to 3. The engorgement of the upper limb and neck veins disappeared on post opt day two and also there was no facial flushing as evident earlier when patient becomes supine or bend down. A repeat colour Doppler of the neck was done on $6^{\text {th }}$ post-operative day, which revealed adequate flow in the bilateral IJV to SVC bypass grafts. Patient was discharged on the $8^{\text {th }}$ post opt day on advice of regular follow up with INR report every monthly.

\section{Discussion}

On deciding on which would be the ideal graft for effective decompression of the venous system of upper limb we would require a graft that would match with the diameters of the IJV and SVC [3]. A routinely practiced the GSV would not be effective for bilateral decompression as the diameters were too discordant, being $6-7 \mathrm{~mm}$ that of GSV, as compared to 12 $14 \mathrm{~mm}$ that of IJV and SVC in our pt.

In our cardiovascular setup we usually use Contegra bovine valved graft for surgical correction of severe pulmonic and infundibular stenosis/atresia and use it as a right ventricle to pulmonary artery bypass conduit graft. No use of contegra valved conduit has been discussed in literature history previously for similar cases. Contegra (Medtronic Inc, Minneapolis, MN), a biological valved conduit consisting of a zero-pressure glutaraldehyde preserved heterologous bovine jugular vein with a trileaflet venous valve with natural sinuses [4]. The claimed advantages of this conduit are constant off the shelf availability, a large variety of sizes available, easy tailoring and suturing, adequate hemodynamics thanks to a favorable effective orifice area, no need for proximal or distal extension, and reduced cost. Added advantage was unidirectional flow [5].

\section{Conclusion}

Balloon dilation and stenting is a safe and effective treatment for brachicephalic vein stenosis and should be considered the first line treatment.But the role of bypass grafting can not be ignored in cases where stenting not possible or the stent was thrombosed. Use of contegra valved conduit was never reported. Cost of contegra and lifelong anticoagulation are the factors should be discussed with patient before surgery.Also our study report is of only a single case with just six months followup. Using contegra graft more frequently with long term followup will give us a better alternative to the PTFE graft in cases where the unidirectional flow is beneficial and mandatory.

\section{Consent}

Informed consent has been obtained from patient.

\section{Ethical approval}

All procedures performed in studies involving human participants were in accordance with the ethical standards of the institutional and/or national research committee and with the 1964 Helsinki declaration and its later amendments or comparable ethical standards. 


\section{References}

1. Patnaik MM, Haddad T, Morton CT (2007) Pregnancy and thrombophilia. Expert Review of Cardiovascular Therapy 5: 753-765. Link: https://bit.ly/2Q3segQ

2. Unsal EE, Karaca C, Ensarí S (2003) Spontaneous internal jugular vein thrombosis associated with distant malignancies. Eur Arch Otorhinolaryngol 260: 39-41. Link: https://bit.ly/39LR9g6
3. Davis D, Petersen J, Feldman R, Cho C, Stevick CA, et al. (1984) Subclavian venous stenosis. JAMA 252: 3404-3406. Link: https://bit.ly/3rNE8c4

4. Gloviczik P, Pairolero PC, Toomey BT (1992) Reconstruction of large veins for nonmalignant venous occlusive disease. J Vasc Surg 16: 750-756. Link: https://bit.ly/3uieCOi

5. Schillinger F, Schillinger $D$, Montagnac R, Milcent $T$ (1991) Post catheterisation vein stenosis in haemodialysis: comparative angiographic study of 50 subclavian and 50 internal jugular accesses. Nephrol Dial Transplant 6: $722-$ 724. Link: https://bit.ly/3wy9R4s
Discover a bigger Impact and Visibility of your article publication with Peertechz Publications

\section{Highlights}

* Signatory publisher of ORCID

* Signatory Publisher of DORA (San Francisco Declaration on Research Assessment)

- Articles archived in worlds' renowned service providers such as Portico, CNKI, AGRIS, TDNet, Base (Bielefeld University Library), CrossRef, Scilit, J-Gate etc.

* Journals indexed in ICMJE, SHERPA/ROMEO, Google Scholar etc.

* OAI-PMH (Open Archives Initiative Protocol for Metadata Harvesting)

* Dedicated Editorial Board for every journal

* Accurate and rapid peer-review process

* Increased citations of published articles through promotions

* Reduced timeline for article publication

Submit your articles and experience a new surge in publication services

(https://www.peertechz.com/submission).

Peertechz journals wishes everlasting success in your every endeavours.

Copyright: @ 2021 Nagre SW, et al. This is an open-access article distributed under the terms of the Creative Commons Attribution License, which permits unrestricted use, distribution, and reproduction in any medium, provided the original author and source are credited.

Citation: Nagre SW, Bhosle KN (2021) Novel use of contegra valved conduits in idiopathic bilateral brachiocephalic vein stenosis. J Cardiovasc Med Cardiol 8(2): 038-040. DOI: https://dx.doi.org/10.17352/2455-2976.000167 